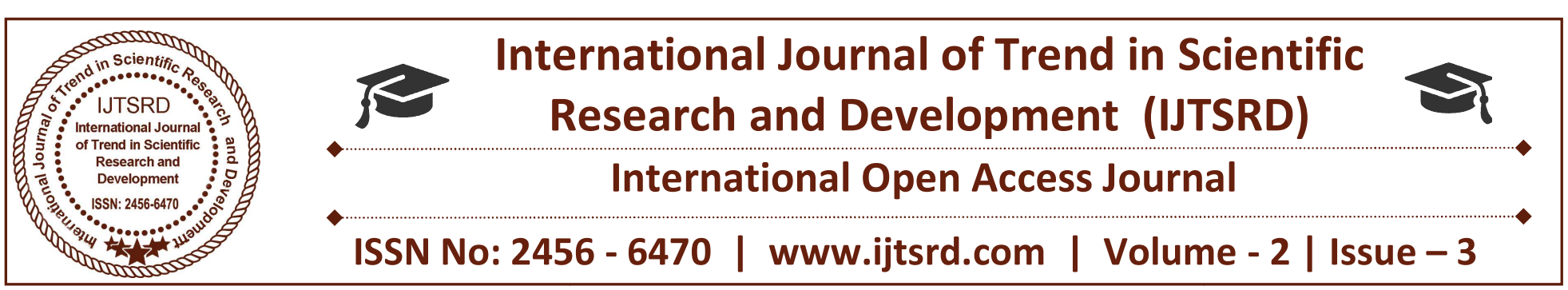

\title{
Exploring the Role of Culture on Graphic Designs
}

\author{
Leena Philip \\ Asst Professor, Center for Management Studies, Bangalore, India
}

\begin{abstract}
Research never concludes because there is always a new perspective that remains unexplored; Somebody starts recognizes it and starts the process again to make a justified contribution. This research also began because of lack of investigation in this field. Relationship between culture and graphic design is abundantly visible, so much that it is politely ignored by us. In this paper two pillars of this century have been examined to help understand the design trends and strengthen them at the foundation. Though culture has been a subject of study for more than a century now but graphic design has gained momentum very recently and it is significant to understand how has it become a part of the already established world; if not then how can it the incorporated into the realm of other fields.
\end{abstract}

Keywords: Graphic design, Culture, Popular culture, color psychology

\section{INTRODUCTION}

Advent of technology has maximised the potential of graphic design. The packaging of a product, posters of concerts, memes on social media, billboards, logos, brochures and various visual elements have revolutionised the communication process of $21^{\text {st }}$ century. Textual communication has become a museum artefact now as visual communication is crowned the new heir of communication. It's not an aide of the elite but the tool of every man. An important sub category of visual communication, graphic design is a popular tool emerged from art and extensively adopted after the invention of printing.

But what have been humans been communicating? As humans began sharing similarities they began grouping themselves. With evolution of human brain, the difference began surfacing and man found himself sharing similarities with multiple groups - common likes, dislikes, profession, values, religion, personalities, etc - this became culture.

This research paper can be broadly placed as a nexus between the fields of graphics and culture and measure their interdependence. The review of literature will dive into both the fields and find commonalities to build this gap and analysis of field work will prove its validity in the $21^{\text {st }}$ century. To analyse the data, visual cognitive theory and design concepts explaining relations between color \& culture, shapes \& culture and structure \& culture are used. Humans are evolving every day; ideas are multiplying; culture is constantly changing; communication methods are revolutionizing but it is important to observe that all of them are walking together towards change.

This paper tries to construct a nexus between two important individual elements which widely impact us and each other - Culture and Graphic Design. To identify how culture impacts graphic design and the degree of impact, I will deconstruct the evolution of culture and graphic design separately in view of etymology, history, anthropology, psychology and sociology suitably. Subsequently, the paper will qualitatively and quantitatively establish the agenda and outline the factors of how culture influences graphic designs of the $21^{\text {st }}$ century.

The origination of both, culture and graphic design, can be traced back to earliest stages of human evolution; yet efforts to adopt them with a definite meaning and use began in the $19^{\text {th }}$ and $20^{\text {th }}$ century 
respectively. Gradually, several interpretations were put forth and debated to reach a consensus. To identify how culture influences the graphic designs created by the designers of the $21^{\text {st }}$ century, it is paramount to look at the different perspectives regarding the two concepts.

\section{DEFINITION OFGRAPHIC DESIGN}

Graphic design essentially emerged as a medium of communication used by the caveman to communicate, store and indicate messages or purpose of the design. Though, it took various forms, predominantly symbols, depending on the necessity in different parts of the world, a common purpose was basic communication. For instance, Egyptians devised Hieroglyphs - colourful illustrations on wood, stones, etc. - to preserve their knowledge on subjects like mathematics for future. Eventually after the phenomenal inventions of alphabets, paper and printing press, conveying of emotions, thoughts, actions and messages took to visual language. Art materialized into an everlasting fad of individual expression enhancing the purpose of illustrations from a mere preservation tool to a skilful communication instrument capable of speaking, persuading and changing attitudes, perceptions and sentiments.

William Addison Dwiggins is credited of coining the term 'graphic design' in an article written for a newspaper in Boston in 1922. A pioneer in print communication and design, he directed his efforts to establish graphic design as a separate subject from art. According to him:

"In the matter of layout, forget art and use horse sense. The printer designer's whole duty is to make a clear presentation of the message. This calls for an exercise of common sense and faculty of analysis rather than of art."

It can be derived that then graphic design was just a message presented in an aesthetically appealing manner. Subsequently, several people supported his efforts and became revolutionaries in the field of graphic design. Richard Hollis in Graphic Design: A Concise History (1994) describes design as

"A form of visual communication and business of making or choosing marks and arranging them on a surface to convey an idea."

Detailing on it he says,
"Graphic design can be signs like the letters of the alphabet or form part of another system of signs; like road markings. Put together, graphic marks - the lines of a drawing or dots of a photograph - form images."

Hollis' at a very initial stage identified what outputs of graphic design can be and like Dwiggins restricted the possibilities of experimenting with it to identify new roles for graphic design. But as popularity of the profession grew, designers explored new avenues and devised multiple purposes to use it.

\section{REVIEW OF LITERATURE}

This chapter reviews the multiple opinions in the fields of culture, graphic design, semiotics, visual communication, art \& art movements and psychology by virtue of existing research papers, books, analysis and other pieces of literature to identify how each of these fields accelerate or decelerate the impact of culture on graphic design. It will also elaborate and apply the concepts of culture on design and viceversa, partially discussed in the previous chapter, to identify the scope of the study.

\section{CULTURE, VALUES AND SYMBOLS}

From the etymological analysis of culture's evolution, it can be observed that culture was used synonymously with civilisation as a general common process of development for everything including living beings until the $18^{\text {th }}$ Century. Besides, the etymological discovery, the $19^{\text {th }}$ and the $20^{\text {th }}$ century has seen invention of multiple avenues, discussed in the upcoming part of the chapter, to explore culture, resulting in rapid transformation in its meaning and usage.

A significant twist in the definition of culture came about when Johann Gottfried Herder in his incomplete book Ideas on the Philosophy of History of Mankind attacked the assumption that historical selfdevelopment of humans, precisely civilisation or culture, was a unilinear process. He generalised culture's use to cultures and hence emerged the idea of specific and variable cultures; cultures which could vary not only amongst different nations and periods but also within a nation's social and economic groups. Later, culture's context expanded to national, traditional and folk cultures. Therefore, culture could now be seen as a process of growth varying between several communities and groups, taking into consideration the factors that differentiate an individual community from others. This realization 
led to researchers, scientists, theorists and professionals to scrutinize the realization that differences exist not only in the process of growth but also in their actions, reactions, beliefs, products they use, artifacts, etc.

One such attempt was made by anthropologists, who study humans of prehistoric times to the recent times. They have contributed largely in understanding the reasons leading to these variations which also came to be known as 'cultural differences'. Cultural anthropology is a branch of anthropology which studies contemporary people and their cultures, both similarities and differences. These 'cultural differences' were identified by cultural anthropologists such as Marco Polo, Ibn Khaldun and French philosopher Montesquieu among others who travelled the world and documented their experiences and observations of communities they encountered. Edward B Tylor, an anthropologist in his book Primitive Culture states "the condition of culture among various societies of mankind is a subject apt for the study of laws of human thoughts and actions'. Hence, it can be ascertained that culture has been a dominant subject of speculation for decades and that there is adhesiveness between culture and human progression. As a result, it becomes immensely important to look at the anthropological perspective of culture.

The primary definition was given by Tylor, as mentioned in the previous chapter, which directed further study in this direction. He characterises culture as "a complex whole which includes knowledge, beliefs, arts, morals, law, customs and any other capabilities acquired as a member of a society". Tylor's assumption that a society progresses from savaged to barbarian to civilised in a universal manner contradicts his definition. According to him, culture is a universal process of growth and the ultimate stage of growth - civilised - is achieved when people are completely 'Westernised'. This implies that all these varying aspects of culture - knowledge, beliefs, arts, morals, law, customs - will become 'Westernised' when the society is completely 'civilised' and hence a 'universal culture' will navigate the progress of the world. His futuristic view is not accountable to the present scenario however his definition does accommodate an important factor that knowledge, beliefs, arts, morals, law, customs are all attributes of culture and can be learnt from a society.

\section{CULTURE, BEHAVIOR AND PERCEPTIONS}

This section takes our understanding of culture to the next level and also substantiates the objective of this study i.e., to connect culture with graphic design. It attempts to address the following hypothesis by reviewing existing literature: perception stems from our learning, behavior and attitudes which in turn are products of culture. One of the first to identify this correlation was Franz Boas whose view has been discussed in the previous chapter. His followers and students initiated a movement in the early $20^{\text {th }}$ Century to bring forth the relationship between culture and personality amongst the other numerous conceptualizations of culture. The culture and personality movement opined that culture influences socializing patterns which in turn shapes some of the variants of the personality; because of distinctive socialization practices, each society has a unique culture. It is learned patterns of behavior transferred along generations and the patterns learnt during childhood play a significant role in shaping a person's character and behavior.

In a research paper published by Harry $\mathrm{C}$ Triandis and Eunkook M Suh, Cultural Influences on Personality, the recent developments with regards to the movement have been traced which reflects that the movement has faced severe criticism as well as obtained substantial support. Arguments stated by one of the critique, Shweder against the initial ideologies of the movement are:

There can be no global human traits i.e., it does not take account of variations in individuals in a society

Early childhood practices may not have predictable consequences for an adult character

As levels of variety between cultures increase, analogies between situations become less significant as there is a decrease in platforms of comparison.

However, he does agree that culture and personality are interdependent. Nevertheless, several researchers have counter-argued in support of the ideals of the movement like McCrae and Lee et al. Research conducted by Digman \& Shmelyov 1996, McCrae \&Costa 1997, Pulver et al. 1995 and Yang et al. 1999 conclude that a common personality structure has emerged between the gamut of cultures existing in the 
world. McCrae along with other researchers have published works in support of the ideologies of the culture and personality movement. Therefore, deductions and fundamentals of this theory can be used as relevant material to support the study.

A prominent supporter of the movement, Robert A LeVine in Culture, Behavior and Personality defines personality in two different contexts: "Personality is the organization in an individual of those processes that intervene between environmental conditions and behavioral response." These processes such as perception, cognition, memory, learning and activation of emotions invoke different responses from different individuals, hence have to be taken into consideration. It is important to note that LeVine includes variability of perceptions and learnings in his assessment of a personality. His second interpretation is: "Personality in a narrower sense, is based on observation of consistencies in a person's behavior in different situations". Personality, here, is an accumulation of a person's traits rather than a process. Often these behavioral consistencies might go unnoticed due to their presence internally.

Harris and Eunkook have developed a new framework to define the association between culture and personality. According to them personality is shaped by environmental as well as biological influences. Amongst all the environmental influences, cultural influences are predominant in designing socializing patterns which in turn shape behavior, which is also one of the core values of culture and personality theory.

Common characteristics can be pointed out in the definitions of Ralph Linton, Margaret Mead and Ruth Benedict, as mentioned in the previous chapter, that culture is learned behavior passed on through generations which shapes perceptions and attitudes. Lederach in his definition points out that culture is shared knowledge used to perceive, interpret, express and respond to the realities around them. Hence, on the basis of the literature reviewed it can be assumed that culture influences personality and shapes behavior and perceptions.

\section{CULTURE AND COMMUNICATION}

It can be observed from the inferences mentioned above that there were two objectives underlying the cultural illustrations, especially the visual manifestations, employed over centuries:
1. To preserve their findings or document their lives, lifestyle, achievements, accounts, etc

2. To communicate or indicate a message amongst a group or several groups. For example, the prehistoric man sketched symbols or processes on caves and stones to record say the process of hunting or rituals like Egyptian hieroglyphics; the Cholan kings of Southern India documented their transactions, crowning ceremonies of kings, festivals, dates, etc. on walls and inscriptions.

Hubert Knoblauchin Culture in Communication Analyses of Intercultural Situations describes Alfred Schütz cultural approach to communication as: "Cultures and civilisation patterns of group of life 'include' all the peculiar valuations and institutions and systems of orientation and guidance (such as folklore, mores, laws, habits, customs, etiquette, fashion) which characterise - if not constitute - any social group at a given moment in history." He says that cultural meanings are derived from negotiations and these negotiations employ communicative actions. Huber proposes that since culture in everyday life is illimplemented with the support of communicative actions, it can be called as communicative culture i.e., communicative culture is produced, realised and transformed in communicative actions in everyday life and is not present in mind or in objectified system of discourse. His outlook of culture incorporates knowledge, meaning, signsystems and predominantly communication.

Investigating further into the theory, Wuthnow proposed that culture consists of discourses, texts, symbolic practices and communicative events that constitute the ongoing stream of life. Later, Wuthnow and Witter stated that, in terms of discourse and practice, culture can be elaborated as a continuous process of meaning construction through communicative action.

Edward T Hall, an anthropologist who has written three books - The Silent Language, The Hidden Dimension and Beyond Culture on primitive humans and culture, says "Culture is communication and communication is culture".

Despite the emphasis laid on communication being culture or a part of culture, in my view, communication cannot be seen as either because as we have concluded in the previous chapter, culture is an assembly of varying individualistic or communal characteristics, thoughts and actions which finds 
expression by means of visual elements. However, communication can be seenas a process which disseminates, deconstructs, analyses and catalyses the growth of culture. As argued above, culture has taken birth by means of communication; but here, I would also like to pinpoint that communicative actions or communication methods are adopted by cultures as per their convenience and understanding of the communication media and process. Hence this study will not abide by the theory that culture is communication. Nevertheless, communication in the context of this research paper will be seen as a carrier of culture. In support of this assumption, I would like to reinstate Robert LeVine's viewpoint on culture:

"Culture is a shared organization of ideas that includes, intellectual, moral and aesthetic standards prevalent in a community and the meanings of communicative actions."

Summarising communication, culture and graphic design, Barnard says "communication in graphic design can be understood as the interaction of beliefs and values held by members of cultural groups and the formal elements of graphic design such as shapes, lines, colour, imagery, text, layout, etc".

\section{VISUAL COMMUNICATION}

As it is evident from the word, visual communication can be interpreted literally as communication by virtue of visual messages. It is a form of non-verbal communication, found by the early man to preserve or communicate. Since then, along with the medium, its purpose and functions have changed tremendously from artistic to commercial to creative and to a popular media.

In the most basic sense, Lester defines visual communication as:

"Visual communication relies both on eyes that function and a brain that interprets all sensory information received ... All messages, both verbal and visual have literal and symbolic meanings."

In his perceptive, visual communication can be understood as a sequential process - see, understand, perceive and build an emotional connection with the content. In a similar view, Bruno Munari in Design is Art explains:

"Visual design is an assembly of images whose function is to communicate and inform visually: signs, symbols, the meaning of form and colors and relation between these."

Arthur Berger in Seeing and Believing describes visual communication from a symbolic angle. According to him, visual communication is primarily "through the symbolic means by words and signs and symbols of all kinds". He also adds that people's emotions, feelings, ideas and notions are reflected, represented, changed, and developed through visual and symbolic expressions. The definitions have two things in common: Firstly, visual communication is a symbolic illustration persuading the viewer to think beyond the obvious. Secondly, a visual design is also a representation of mind ie., one aspect of a designer's creation is his/her visual perception of his surroundings. What we see is how we interpret and often unknowingly invisible factors moulds human perception. Hence, we need to examine how a we perceive visual elements and what effects his/her view.

Aldous Huxley in his book The Art of Seeing (1942) describes seeing as a combined process of sensing, selecting and perceiving. According to him:

Sensing is function of eye i.e., to identify and see without any activity of mind being involved.

- Selecting is an intellectual activity of selection by your sub-conscious mind on the basis of certain emotions the viewer feels about the object like attractive, harmful, unpleasant from the visual array before you.

- Perceiving is to derive a meaning in a field of view i.e., a particular subject, from the observation captured by your eye to make it more clear.

Connie Malamed in Visual Language for Designers: Principles of Creating Graphics that People Understand says "We understand images rapidly scan, search our memory storage to recall forth association and use what we already know to interpret meanings." Quoting a study mentioned in the book which intends to analyze the intended meaning and perceived meaning, findings revealed that more than half of the time visuals were misinterpreted. The study concluded as "Despite what appears to be a cross-cultural ability to recognize objects depicted in pictures, the visual content of an illustration is frequently a vehicle to communicate a more complex meaning or intention. Unlike the subject content of 
the picture, this intended meaning may often be misunderstood or unrecognized by the viewer."

In Visual Communication - Images with Messages, Lester elaborates on a psychological perspective of visual design termed as visual theories. He classifies it into two as sensory and perceptual theories. Sensory theories will concentrate on Gestalt theory and Constructivism and perceptual theories will adhere to cognitive theory and semiotics; however, since the topic of concentration is perception of visuals, perceptual visual theories will be detailed and analyzed.

\section{COLOR PSYCHOLOGY AND CULTURE}

Why does a funky yellow color catch your gaze amongst plethora of items before you? Why do doctors wear white coats? Why does fire invoke passion and fury? These questions did not pop up until artists, anthropologists and psychologists discovered the importance of colors, saw their capability to convey different meanings and alter perceptions. In Design Elements - A Graphic Style Manual, Timothy Samara says "With color comes variety of psychological messages that can be used to influence content... These psychological properties of color also highly depend on a viewer's culture and personal experience." For example, black color indicates mourning for Christians while for Hindus white is associated with death and mourning. Red is food \& hunger for some culture while some other cultures might associate it with violence. Hence, every color is selected by a designer to imply a meaning. If this is true, then it can be rightly assumed that a graphic designer's perceptions of these colors are influenced by his choices of colors.

Several theories were proposed to relate visual elements and properties of colors. One of them is the Wright Theory ofColor Symbolism which explains that colors are used as symbols to denote some meaning. For instance, the color orange is a symbol of humility and sanctity in Buddhism, while in Japan it depicts love. Orange may also remind people from US or Ireland of Halloween and if you observe is often the color used in the logos of food condiments, restaurants and food-chains. John Gage in Color and Meaning: Art, Science, and Symbolism also states that these kind of associations can also be inspired from natural phenomena and objects. For example, the color yellow reminds us of Sun and green reminds us of greenery because we identify them from nature.
The cause lies in the root fact that any human being even before gaining the sense of differentiation or identification lives in the shade of nature natural objects activate his dormant senses.

In a research conducted by Global Propoganda, a Spain based organisation titled as Colours Across Cultures: Translating Colors in Interactive Marketing Communications emphasise that every color has a cultural connotation for people varying with age, gender, climate, linguistic relativity, etc. A survey was carried out for 4 cultures (Japan, China, South Korea and USA) asking the sample to one of the 8 colors with 13 words often used to describe them. The results indicated some similarities and some dissimilarities. All of them associated blue with high quality whereas only three of them associated purple with expensive and US associated it with inexpensiveness. Many such examples which go unnoticed can be observed from our routines to substantiate the concept discussed here.

\section{RESEARCH METHODOLOGY}

A research always begins with a hypothesis that the researcher wants to scrutinize and reach a conclusion. An important aspect of research is the methodology or the methodical structure adopted, as the right methods can lead to efficient results while unsuitable methods can lead to undesired results. Hence, it is pivotal to have a planned, structured and estimated Research Design. There are multiple resources to conduct a research and acquire substantial data. This chapter will detail the methodology and approaches adopted to explore the hypothesis of the researcher to accomplish the set objectives.

\section{OBJECTIVES}

To recognise if graphic design is a cultural manifestation

To outline the aspects of culture which impact a graphic designer's thought process

$>$ To identify if culture affects a graphic designer's creations in the $21^{\text {st }}$ Century

\section{SAMPLING}

To decide on the sampling, the researcher has referred to Raosoft Inc, an online portal which develops softwares to conduct surveys. One of the programs developed by it is a sample size calculator which gives an estimated sample size a surveyor should use 
to conduct the survey. The software estimated the sample size for this research to be 204 on the basis of the below mentioned variables:

- Margin error: This is the amount of tolerable error for the survey. For the purpose of this research it was chosen as $5 \%$. For instance, for a particular question, if the respondents are classified as $60 \%$ and $40 \%$, then a margin error of $5 \%$ is acceptable as the majority will still remain the same.

- Confidence level: This is basically the amount of uncertainty that can be tolerated for every question. Since, for a higher confidence level the required sample size is more, the chosen confidence level was $85 \%$.

- Population size: This is the actual size of the population from which the sample is chosen. The chosen population size is 10000 .

- Response distribution: This gives you the estimated distribution of the responses. The distribution was assumed to be $50 \%$ as the researcher is not aware of the possible reactions that the sample size would give.

The calculated sample size is the minimum amount of responses to be obtained to get a fairly accurate outcome.

Quantitative research methodologies were adopted to study a focus group consisting of 40 people residing across Bangalore, Karnataka aged above twenty years. A varied chunk of the large population of professional graphic designers working in Bangalore were chosen, with the least experience of 1 year to the highest experience of 25 years to ensure that age becomes no barrier to the set objectives. A homogenous sample group i.e., all working graphic designers, contained amateurs and professionals hired by companies and self-employed designers i.e., freelancers. Since age was no restriction and the focus group consisted localites as well as migrants the research was conducted on people from different cultural backgrounds.

\subsection{METHODOLOGY}

Here, the researcher would like to emphasise on the process elucidated by CaroleGray and Julian Malins in Visualizing Research - A Guide to Research Process in Art and Design. They say research is a process of accessible disciplined enquiry in the area of interest and 'Methods' are specific techniques and tools for exploring, gathering and analysing information, for example, by observation, drawing, concept mapping, interviews, case studies, visual diaries and so on. Finally, Methodology is the study of the 'system of methods and principles used in a particular discipline. This substantiates the methods adopted in this research by drawing lines of difference as to how a visual research take a different turn in methods adopted compared to other research methodologies.

As declared above, quantitative inferential and experimental approaches were used to obtain statistical data from 37 samples. The samples were made to fill up a questionnaire with 10 questions each serving a sub-objective to draw analogies and conclusions leading to the final objectives. The first two questions intended to measure the orientation of the designers towards modern forms and traditional forms of graphic design. This set of questions also indicated to what extent traditions were passed on over the generations of a culture and if they continued to be implemented or not.

The next four questions were based on the fundamental elements of design - color, structure, shapes and layout. Many scholars, learned designers and researches claim that there exist multiple patterns of arranging these elements; and every position and use has an association with a personality type which directs us to a cultural motive or learning. These cultural manifestations in designs masked behind design elements are often non-deliberate actions oblivious to their cultural impositions.

The final set of questions were integrated with graphic designs positioned according to the three most practiced structures - top-bottom, center and leftright; created by appreciated and learned designers of different time periods \& countries like Paul Rand, Saul Bass, Milton Glaser and Prajit Anand; and graphic designs created during different art movements, to locate if there existed any similarities between the cultural ethos and style of designing of the time period and the sample designer. They also attempted to estimate the symbolic value, of the different kinds of symbols used in the designs, a graphic designer holds. A detailed description in the next chapter will illuminate the significance of the theories proposed above and how they were used to analyse the questionnaire and the responses. 


\section{DATA ANALYSIS AND FINDINGS}

A graphic designer is ideally supposed to create designs that are aesthetically appealing and saliently communicating the message. Along with these two primary rules, it is necessary to acknowledge that his designs are accountable to his clients or brands. Therefore, he creates graphics for a particular target audience. Hence, it can be argued that a designer is tamed by popular demand and has less creative freedom to give his own culture space in the design. This chapter will make efforts to justify the stance taken by the researcher against the above argument and provide evidence to prove the objectives.

A sample size of 40 graphic designers from across Bangalore were made to fill questionnaires. The questions aimed at analysing the cultural facet of primary design elements - color, structure and shapes - with reference to the concepts of color psychology, Kress \& Leeuwen's analysis of structure, shape symbolism and cognitive theory discussed in the previous chapters. Each of the questions from the questionnaire is framed to ultimately accomplish the objectives of this study. The following section will elaborate on each question stating the terms on the basis of which conclusions are drawn.

The first question posed was on the type of aids used by the designers to recreate their ideas on a visual platform. The results reveal that $67.5 \%$ of them prefer to use a combination of digital aids (softwares like Adobe Photoshop, illustrator and Coral draw) and traditional aids (pencil sketching, layouting, coloring, etc.). However, despite the rapid advancement in technology for graphic designing only a meagre $15 \%$ prefer only digital aids and interestingly $17.5 \%$ of them still prefer only traditional methods. This indicates that $85 \%(70.3+13.5)$ of the designers still actively use traditional methods of designing. Applying the same calculation technique, it is found that $82.5 \%$ are active users of digital methods. Interestingly, the traditional methods overpower the utilization of digital methods indicating that cultural influence prevails in the initial process of designing as traditional methods have been passed through generations. These methods vary because they have been adopted from their distinct cultures.

The second question was to determine the reference frame from where the flow of ideas begun in a graphic designer's mind. They were asked, to which form of art did they refer - traditional or modern. 52.5\% said that both traditional and modern art were their inspirations; $35 \%$ stressed on only modern art being their reference while $12.5 \%$ said they referred to traditional art. On analysing it further, it was found that this population falls in the age group of 20-25 years and may not relate to traditional art. Although comparatively less, $68 \%$ of the sample refers to traditional art. But in the previous question it was found that $85 \%$ of the population used traditional methods. Thus, there is a possibility that traditional art has found identity and purpose in new forms of modern designs.

The next set of questions will build conclusions by speculating the usage of three graphic design elements - color, followed by shaped and structure. To serve the purpose, the designers were asked to choose a color that dominates his/her graphic designs. Figure 3 clearly establishes the allegations of the concept of color psychology.

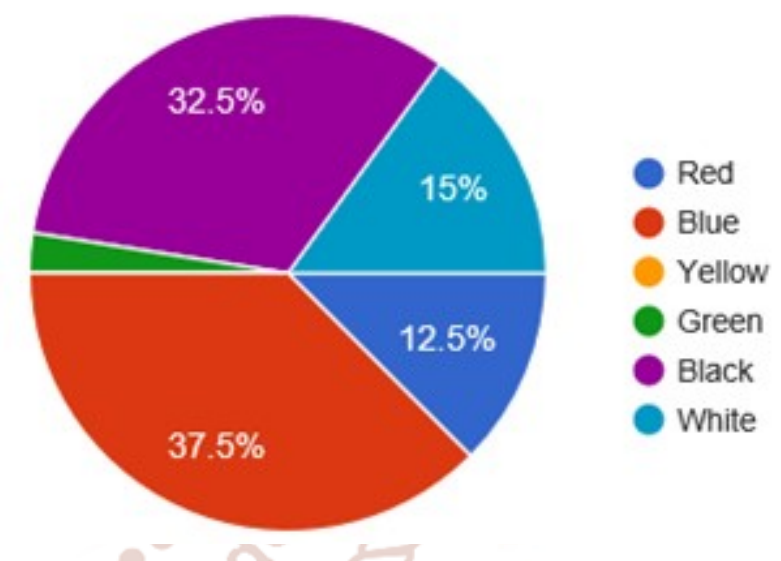

Figure 3

It is evident from the chart above that five colors of the six options have found a considerate amount of usage which implies that the sample group is made up of designers whose choices are different and these choices are not bound by creative usage i.e., there is diversity of choice amongst diverse people. The rationale behind restricting the options to only these six colors is that they are primary (red, blue, green and yellow) and neutral (black \& white) colors respectively. This implies that there exist factors which govern every individual graphic designer's color choice. It is already known that two of the factors which effect this choice are color symbolism and culture. Another possibility could also be favouritism towards a color i.e., liking or disliking a color which can lead to often or rare use of a color, but, again the liking or disliking might be influence by 
culture. Every color provokes an emotion and a reaction and this happens because of the cultural values a person has imbibed since birth.

It can be countered that since the choice was restricted, designers were forced to choose one of them but it cannot be neglected that usage of primary colors cannot be avoided; secondary and tertiary colors are a combination of primary and neutral colors.

The fourth question examined the shape preferences of the designer. Only primary geometrical shapes were used as they have found wide application in design, in the bygone and in the contemporary era. Therefore, a just analogy can be formulated. Secondly, the other two types of shapes were not considered because there is no clarity on what an abstract shape is; they are innovative elements whose interpretation may vary from person to person. The purpose of such creations may itself be very abstract and may not find use beyond a couple of designs. Another category of shapes is organic shapes. These shapes either represent natural elements \& natural phenomenon or are inspired from nature. More than often they indicate a universal meaning as nature is visually constant and alike everywhere.

The question posed was that if given a design, in what shape would the designer inscribe it. As presented in the figure below, $45 \%$ of them chose to inscribe it in a circle, $30 \%$ chose to inscribe it in a rectangle, $15 \%$ in a triangle and $10 \%$ in a square.

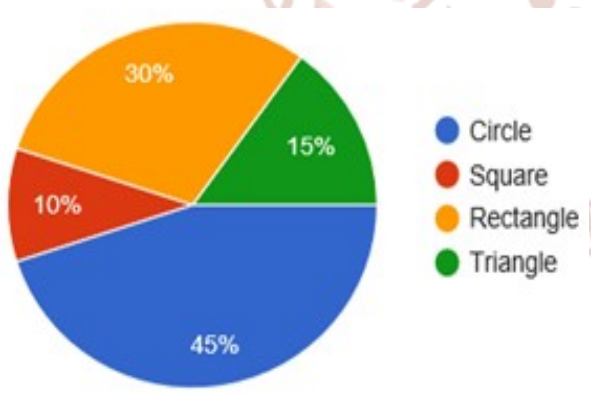

\section{Figure 4}

Before analysing the responses, I would like to list the psychological meanings associated with the four shapes and subsequently connect it with cultural connotations:

Circle: Circle evokes completeness, infinity and unity. Since, it is a closed boundary with no beginning and no end, it is believed to keep away the unwanted, to protect against them. It also suggests integration and perfection. Often circular objects attract attention.

Square and Rectangle: Squares and rectangles are the most commonly used symbols as they denote trust, honesty, rationality and order.

Triangle: They represent dynamicity, action, aggression and tension. Its trio structure has led to its association with several trios like birth, life and death etc.

It is necessary to note that every shape has gained certain importance in the realm of graphic design of designers. The evident affinity towards circle is because of the multiple cultural connotations it has in several cultures. Some cultures are violent, some are peaceful, some worship stones while some worship nature, some respect alcohol while other deny it. Every culture has principles which are reflected are in the colors and shapes they use. The above results suggest that $45 \%$ of the sample designers were from cultures which believe in unity, completeness and are against intrusion; $40 \%(30+10)$ are from a cultural background which believe in logic and discipline; $15 \%$ are from a cultural background which is aggressive and dynamic. These conclusions are an attempt to trace the cultural background and primarily prove that cultural learnings and exposure has led the designers to choose a particular shape over the other. The above inferences may however be subjective.

The results prove an undisputable affinity of the designers towards structural arrangement of design elements as $35 \%$ of them have expressed solidarity with structural arrangement in design, $12.5 \%$ have opted for a more structural and controlled amount of haphazardness in a design and $40 \%$ of them have chosen to have both in equal amounts. According to popular opinion, structural arrangement in design reflects clarity of mind and ensures explicit communication whereas haphazardness reflects disorganization and instability and may not convey the exact message. The designers who have chosen haphazard arrangement of elements may have cultural values of abstractness or aggression. For example, Pop art and Punk art meant to be understood only by their cultural group often employed haphazardness in their posters and other graphic material.

The outcome demonstrates that the most preferred structure is the 'center-margin' structure and as inferred by Kress \& Leeuwen it has been practiced the 
most by eastern countries of which India is also a part. Applying the concept, it can also be inferred that the $30 \%$ designers who prefer left-right structure and $12.5 \%$ of the designers who prefer top-bottom structure have been influenced by Western culture. Either ways, it can be concluded that structural preferences have cultural influence.

A majority of $77.5 \%$ of the designers said that they consider symbolic meanings of design elements while $22.5 \%$ did not see it essential. This is an explicit evidence to claim that culture has influence on graphic design. Of the $22.5 \%$, most of the designers take inspiration from modern art or a combination of both which implies that according to them modern art has no symbolic references. However, modern art also utilizes symbolic references. Since they do not regard symbolic references, they do not see importance of culture in graphic design. This does not evade the possibility of cultural influence on their design because this influence, as projected earlier, is innate.

For the next two questions again graphic designs were used to recognise the style of the graphic designers. The eighth question utilized designs of famous graphic designers - Paul Rand, Saul Bass, Milton Glaser and Prajit Anand - from different eras and with different styles.

A designer is able to build associations with a design that is familiar in any manner. Analysing this bit of the population further, it is found that $48 \%$ have regarded center-margin structure as their preference. Hence, two traits point that the designers share characteristics of eastern culture or rather are influenced by eastern culture in their design choices.

The least chosen was Paul Rand's design as very few could associate with his style of designing. The possible reasons could be that he belongs to an era with which the designers could not associate. Paul Rand is also from a different culture; hence, they could not build associations with his designs. However, Design1 by Milton Glaser built a rapport with a few designers as Milton Glaser continues to design in the time period to which the designers belong, they have lived through similar political and social situations, hence the designers are able to interpret the design elements as Milton Glaser does.

From the results, it can be deciphered that $50 \%$ of the designers were happy and $37.5 \%$ were motivated i.e., the designs evoked positive emotions. If looked at it reversely, it is also possible that the designers chose those designs which gained a positive reaction from them. Every culture yearns for optimism and hope. Hence, not only their style but also their cultural values helped them pick a design.

The above survey only attempted to identify if the graphical manifestations of the designers had any cultural influence. The questions were framed such that by virtue of the design elements, style of designing and their preferences, the possibility of cultural linkages could be studied. The outcomes have proved that there exists cultural influence which may be involuntary and sublime i.e., a designer may incorporate a cultural symbol in a design to create an impact, nevertheless, he is usually unaware of why he selected that particular symbol over the others. The answer lies in the cognitive theory discussed in the earlier chapters. Human memory, expectations, previsualisations, dissonance, culture and habituation regulate these choices. Though these visual theories are applicable to any human being, its relevance to a graphic designer is stronger because a he/she possesses more artistic knowledge and understands regulation of these fundamentals better over others. Moreover, all these theories are formulated by designers or design researchers and hence find application in graphic design abundantly.

\section{SUMMARY}

In a nutshell, the above analysis can be concluded as an evidence to the objectives of the study. By reviewing literature, the researcher found sufficient studies to claim the first objective to be true i.e., graphic design is a cultural manifestation. In the data analysis it is found that different graphic designers have different preferences of colors, structures, shapes and associate with designer of same culture. History of art movements like Art Nouveau, Bauhaus, Dada also substantiates the claim. The second objective was to find cultural aspects which impact a graphic designer's thought process; the data analysis shows that graphic elements like color, shape and structure are aspects of culture. Apart from these, visual perception and communication are also aspects of culture. Since, culture and graphic design have common facets, the second objective is satisfied. And finally, the third objective which aimed at investigating the impact of culture on graphic design in $21^{\text {st }}$ century. The focus group belonged to $21^{\text {st }}$ century apart from which a few of the designs employed in the questionnaire also belonged to the 
designers of $21^{\text {st }}$ century. Therefore, all the three objectives were accomplished.

\section{CONCLUSION}

Research never concludes because there is always a new perspective that remains unexplored; Somebody starts recognizes it and starts the process again to make a justified contribution. This research also began because of lack of investigation in this field. Relationship between culture and graphic design is abundantly visible, so much that it is politely ignored by us. In this paper two pillars of this century have been examined to help understand the design trends and strengthen them at the foundation. Though culture has been a subject of study for more than a century now but graphic design has gained momentum very recently and it is significant to understand how has it become a part of the already established world; if not then how can it the incorporated into the realm of other fields.

Graphic design, years ago, was a low culture - less known and less acceptable, but it never faced resistance as the it was a visual treat difficult to deny. However, as possibilities expanded, people saw potential in its use and today, in the 21 st century it has transformed to become a popular culture used by rich and poor, elite and middle-class equally. Internet is smeared with graphic designs created by professionals and layman for purposes big and small. Therefore, this paper is an academic contribution to the field of graphic design which intended to understand a designer's psyche and influence of culture on his graphic designs.

The researcher contemplates the contributions of scholars, theorists, anthropologists and designers to this field and locates elements which can help bridge the gap. Culture is analysed from the perspective of symbols, personality, behaviour, perceptions, cultural manifestations and communication; graphic design is proposed as a subset of visual communication and is analysed on the basis of design elements - color, shapes, structure, form - visual sensing, visual perception and communication. Finally using quantitative methods, a field study is conducted and from the data conclusions are drawn. It is proven that culture and values are exhibited in graphic design by virtue of elements of design and a designer's selection of these elements separates him/her from the designers belonging to a different cultural group. On the basis of Raymond Williams explanation, even graphic design can be termed as a culture, however, since the objective investigative culture's influence of graphic design, the vividness in the field has to neglected.

Having said that, there are limitations to this research which need consideration before accepting the conclusion. Firstly, culture's reliability on anthropological evidence and observational data makes the subject ambiguous in nature. Culture is constantly evolving and human perceptions are extremely different and dependent on multiple factors of which culture is just one. Hence, the findings are purely from the cultural perspective. Secondly, from the data it is only possible to show cultural influence and not trace back a person's culture to a specific one because every person is multicultural i.e., he/she belongs to several cultures on the basis of profession, nation, religion, preference, hobbies, values and beliefs, etc. Thirdly, it has not been possible to record statistical data on culture as it vast and equally vivid. As a result, this research cannot take reference from anything but observational data recorded by scholars and theorists.

At many junctures in the process of achieving the objectives, the researcher could not find references to help in solving problems which is a reason good enough to say that all the potential of the field is not completely utilised. It is recommended that designers and students explore this topic more as this will not only quench the modern world's thirst for 'new and unique' but will also contribute in preserving India's cultural heritage.

The researcher would like to acknowledge that this is cannot be the final conclusion on the topic as due to time constraints, lack of sufficient existing study in the field and smaller sample size as compared to the required amount, all the possibilities may not have been accommodated. Although, this can be regarded as a beginning to get a deeper insight into the field. This paper has exploited the potential of the topic to the possible limit but the scope is much larger as the analysis was restricted only to the city of Bangalore. Graphic design is a popular culture world-wide and further research into the field will create new avenues of creativity. 
International Journal of Trend in Scientific Research and Development (IJTSRD) ISSN: 2456-6470

\section{BIBLIOGRAPHY}

1. Di Luzio, Aldo, Susanne Günthner, and Franca Orletti, eds. Culture in communication: Analyses of intercultural situations. Vol. 81. John Benjamins Publishing, 2001.

2. Shweder, Richard A., and Robert A. LeVine. Culture theory: Essays on mind, self and emotion. Cambridge University Press, 1984.

3. LeVine, Robert A. Culture, behavior, and personality. Transaction Publishers, 1982.

4. Barnard, Malcolm. Graphic design as communication. Routledge, 2013.

5. Jobling, Paul, and David Crowley. Graphic design: reproduction and representation since 1800. Manchester University Press, 1996.

6. Arisman, Marshall. "Is There a Fine Art to Illustration?." The Education of an Illustrator (2000): 3-4.

7. Williams, Raymond. Keywords: A vocabulary of culture and society. Oxford University Press, 1985.

8. Logan, Peter Melville, "On culture: Edward B Tylor's Primitive Culture, 1871"

9. Banks, James A., and Cherry A. McGee Banks. Multicultural education: Issues and perspectives. John Wiley \& Sons, 2009.

10. Paul, Rand. "A Designer's art/Paul Rand." (1985).

11. Kress, Gunther R., and Theo Van Leeuwen. Reading images: The grammar of visual design. Psychology Press, 1996.

12. Panneerselvam, R. Research methodology. PHI Learning Pvt. Ltd., 2014.

13. Kothari, Chakravanti Rajagopalachari. Research methodology: Methods and techniques. New Age International, 2004.

14. Helfand, Jessica. Screen: Essays on graphic design, new media, and visual culture. Princeton Architectural Press, 2001.

15. Berger, Arthur Asa. Seeing Is Believing: An Introduction to Visual Communication. Mayfield
Publishing Company, 1240 Villa Street, Mountain View, CA 94041., 1989.

16. Boas, Franz. The mind of primitive man. BoDBooks on Demand, 2013.

17. Malins, Julian, and Carole Gray. Visualizing Research: A Guide to the Research Process in Art and Design. Ashgate Publishing, Ltd., 2013.

18. De Bortoli, Mario, and Jesús Maroto. "Colours across cultures: Translating colours in interactive marketing communications." European Languages and the Implementation of Communication and Information Technologies (2001).http://globalpropaganda.com/articles/Trans latingColours.pdf

19. Triandis, Harry C., and Eunkook M. Suh. "Cultural influences on personality." Annual review of psychology 53.1 (2002): 133-160

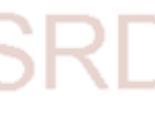

